\title{
The deadliest tropical cyclone 'Amphan': investigate the natural flood inundation over south 24 Parganas using google earth engine
}

\author{
Bijay Halder ${ }^{1}$ (D) Suman Das ${ }^{2} \cdot$ Jatisankar Bandyopadhyay ${ }^{2} \cdot$ Papiya Banik $^{3}$
}

Received: 12 April 2021 / Revised: 12 May 2021 / Accepted: 13 May 2021 / Published online: 22 May 2021

(C) The Author(s), under exclusive licence to Springer Nature Switzerland AG 2021

\begin{abstract}
Climate change is hammering the environment, socio-economic condition, vegetation degradation, earth surface change and over the land losses. In between 2019 and 2020, West Bengal people are facing three major cyclones like, Fani, Bulbul and the last was Amphan. Those natural disasters were affected in vegetation, hammering crop production, water quality change, life losses and affected in the ecosystem. 20th May 2020 Amphan was entering in West Bengal and occur several damaged. Seventy two people of West Bengal were lost their life and several months over the southern parts of West Bengal are facing huge land scarcity and salt-water intrusion on the mainland. Over 13.6 billion dollar was losses due to this cyclone. Google Earth Engine (GEE) is a cloud-based platform to detect earth observation using high spatial satellite data with planetary-scale analysis capabilities. C-band Sentinel-1A Synthetic Aperture Radar is used to identifying the flood inundation on Google Earth Engine (GEE). Landsat 8 OLI data is used for MNDWI calculation on this area. Pre-Amphan and during Amphan two satellite data are clearly showing the water increased area. The Coastal area like Sagar Island (154.254 Sq.km), Ghoramara Island, Mousuni Island, G-Plot, L-Block and some parts of riverside most affected by this cyclone. Kultali (187.254 Sq.km) followed by Kulpi (156.86 Sq.km), Namkhana (198.485 Sq.km) and Basanti (129.53 Sq.km) area under flooded during this cyclone. During COVID-19 pandemic, social distancing is the main problem on cyclone shelter house and relief camp. This area has faced those two disasters at the same time.
\end{abstract}

Keywords Bay of Bengal · Cyclone Amphan · Sentinel-1 SAR data $\cdot$ MNDWI · Flood hazard · Google earth engine

\section{Introduction}

Floods are the maximum frequent on the coastline and it causes several natural disasters. In the year of $2018,50 \%$ of the total disaster-affected people and $24 \%$ of disaster-related death occur in the worldwide coastline. Indian Sundarban area

Bijay Halder

halder06bijay@gmail.com; http://orcid.org/0000-0002-4279-5214

Suman Das

http://orcid.org/0000-0002-1470-782X

Jatisankar Bandyopadhyay

http://orcid.org/0000-0003-2201-7105

1 Department of Earth System Science, Vidyasagar University, Midnapore, India

2 Department of Remote Sensing and GIS, Vidyasagar University, Midnapore, India

3 Department of Geography, University of Calcutta, Kolkata, India is most vulnerable due to some natural disaster like a cyclone, flood, shoreline change and many geomorphological changes. Monitoring any disaster-related effect is the essential part (Carreño Conde and De Mata Muñoz 2019; Kwak 2017; Rahman and Thakur 2018). The most problem are faced during flood area that, public safety, economic loss and cropland damage. The flood monitoring using ground data, satellite observation or flooded area mapping are time-consuming and need a skilled person for this (Rahman and Thakur 2018). Availability of satellite data is more useful for detecting flood-affected area.

The major coastline in the worldwide is threatened from a various natural disaster like cyclone and storm surges. 'Cyclone' the term is used for tropical and sub-topical weather system where the winds equal to the minimum of 34 knots or $62 \mathrm{~km} / \mathrm{h}$ (Mohapatra 2015). Cyclone is one of the natural disasters of every location. The cyclone was created in the ocean and increased their energy and footstep towards the land. Anti-clockwise and Clock wise cyclone are creating into the ocean. The cyclone eye defines the deathly effect of the 
cyclone. As per cyclonites, after touching land the cyclone has decreased the spread of wind. Amphan, almost 16 years ago Thailand has created this name for a tropical cyclone. Thai originates 'Um-pun' means the sky, named in the year of 2004. According to Indian Meteorological Department (IMD- https://mausam.imd.gov.in/), Amphan is the strongest cyclone ever recorded in the Bay of Bengal after 1999. During 2009, the 'Aila' cyclone was one of the effective cyclones ever. Several damaged and areal change were created by this cyclone. Amphan began hitting in the Sundarban area of India-Bangladesh area. Still, 72 people of India and 112 people of Bangladesh died to dup this deathly cyclone. Most of affected area was southern parts of Indian State West Bengal, like Kolkata (Capital of West Bengal and past capital of India) , Purba Medinipur, North 24 Parganas and South 24 Parganas. Huge amount of economic loss occurs in West Bengal during the COVID-19 pandemic. It is the effectiveness challenge for the administrator of each region to build the sustainable situation during two natural disasters like COVID-19 and the Amphan.

Disaster discusses an emergency produced by natural hazards or human-induced movements those results in an important change in environments over a comparatively short period. The results are death, displacement, disease, and loss of crops production. Also, the disasters are effected several damage like physical infrastructure, exhaustion of natural and social resources, institutional weakening and a general interruption of economic and social activity. Disasters may differ somewhat in the trigger, scope, duration and requisite actions (Coletta 2004; Olorunfemi and Raheem 2013). The global consequence relative to disasters is depressing. World statistics indicate contemporaneous and future trends of cumulative influences from natural and anthropological hazards on life and livelihoods (Van Niekerk 2006). In the past era, hazards like earthquakes, drought, floods, storms, fires and volcanic eruptions have effected several damaged and losses of human life and livelihoods; the devastation of economic and social infrastructure and huge amount of environmental damage. Natural disasters like earthquakes, floods and hurricanes can distribute out years of urban development by destroying infrastructure and housing and by injury or killing thousands of people. The 2011 Tsunami in Japan is an example of a disaster categorized by a massive loss of lives and property.

Due to large scale air mass rotation around a strong centre of low atmospheric pressure the spiralling wind is created by the cyclone. Several damaged was occur during the cyclone. Normally the intensity of the cyclone and wind speed is the reason for coastal climatic degradation of an area. Many natural bridges were breakdown and occurring flood on that area. Vegetation areas were huge change and economic losses happen during this natural disaster. In the previous era, India has facing huge amount of cyclone and the results were land reimbursements, life loss, scarcity of socio-economic condition and many more. The southern parts of West Bengal facing huge amount of rainfall, storm and suffers electricity problem. In this study investigate the overall damaged due to flooding on this area, areal condition and economic loss on this area.

Since 2015, advanced GEE cloud-computing platform crate one stage forward to the EO satellite data user community. Earth Engine is a platform for scientific examination and visualization of geospatial datasets, for research, non-profit, academic, business and government users (FAQ-Google Earth Engine). Using GEE tools, users can analyse geospatial information like forest and water coverage, agricultural fields, land use change detection and many passible arena. GEE allows to upload own or created raster or vector data (Area of Interest/Region of Interest) for analysis. The Google Earth Engine is a cloud computing platform to store and process huge amount of datasets (at petabyte-scale) for analysis and ultimate decision making (Kumar and Mutanga 2018). The GEE has used all the dataset of Landsat, Sentinel, MODIS and many more for their cloud computing engine to easily access, modifying and manipulation as users choose. The GEE user can use this cloud computing platform for their dataset collection, change detection, map trends, LULC classification, NDVI, EVI, NDWI, NAIP data, Sea Surface Temperature data, CHIRPS climate data and many more using JavaScript and Python programming (Mutanga and Kumar 2019). The GEE platform included remote sensing data, a large amount of vector, raster, social, demographic, digital elevation models, and cloud 1 cover already add to this platform. Raw imagery is available, along with cloud-cleared and mosaicked imagery (Introduction| Google Earth Engine). Some of the datasets have been converted into raw digital numbers to top-of-the-atmosphere reflectance and even surface reflectance, translation then the suitable for future analysis without needing specialized software for the solar and atmospheric corrections of the imagery (Kumar and Mutanga 2018).

The estimated image can export from Earth Engine in GeoTIFF or TFRecord format.

The radar data needs numerous specialized algorithms to estimate calibration, orthorectified imagery also preprocessing of Sentinel-1 data in GEE (Sentinel-1 Algorithms). The Copernicus Sentinel-1a and 1b Synthetic Aperture Radar (SAR) satellite platforms, with the spatial resolution as low as $20 \mathrm{~m}$ depending on the acquisition mode, combined revisit times is twelve day and complete from solar illumination and cloud cover, EO data for change detection analysis (Canty et al. 2020). The GEE platform includes in extensive up-to-data archive, Sentinel-1 dual-polarization (vertical transmission and vertical and horizontal reception over the land surface) multi-look data format (Gorelick et al. 2017; Mutanga and Kumar 2019). Change detection analysis 
using GEE Sentinel-1 imagery in the forest or overall land use based on Otsu thresholding (Otsu 1979) and K-means clustering (Dostálová et al. 2016). The change detection procedure for multi-look SAR datasets including test statistic for the equality of polarimetric convenience metrics assumed to follow a complex Wishart distribution (Conradsen et al. 2003). The GEE Sentinel-1 intensity develop into $2 * 2$ convenience matrix without the multifaceted off-diagonal elements, these datasets are not available on this platform (Canty et al. 2020). Also, Synthetic Aperture Radar (SAR) is very useful for flood monitoring because of their exclusive cloud, rain and haze penetration capacity. These advantages are used for the realtime observation of flood assessment. The most important advantage of SAR data is that land and water contrast can be easily notable. SAR sensors are able to detect the flooded area because of their flat surface reflect (as a specular reflector) the SAR data signal away from the sensors, decreasing the amount of returned radiation (Gan et al. 2012). In the last decades, microwave SAR data is used for worldwide mapping and monitoring of hydrological parameters (Voigt et al. 2009). Particularly, the SAR data is used for large and small scale flood mapping and monitoring of an area.

\section{Cyclone intensity}

The super cyclone storm 'Amphan' over the west-central Bay of Bengal moved nearly the northwards with the speed of $180 \mathrm{~km} / \mathrm{h}$ lay centred at 19th May 2020. The actual location of this cyclone is $17.0^{\circ} \mathrm{N}$ latitude and $86.9^{\circ} \mathrm{E}$ longitude over west-centre Bay of Bengal. The cyclone situation is around $360 \mathrm{~km}$ near of Paradip (Odisha), $510 \mathrm{~km}$ south-southwest part of Digha (West Bengal) and $650 \mathrm{~km}$ south-southwest part of Khepupara (Bangladesh). The Amphan cyclone reaches Sundarban during the afternoon to the evening of 20th May 2020 with the maximum wind speed of $155-165 \mathrm{~km} / \mathrm{h}$ gusting $185 \mathrm{~km} / \mathrm{h}$ (IMD-INCOIS report, 19th May 2020).

\section{Study area}

The Ganga-Brahmaputra-Meghna delta is the largest delta in the world and it is located in the southern part of Bengal basin. These delta areas have two parts, one is Bhagirathi-Hoogli river area and the other is PadmaMeghna estuary. The coastal region of GangaBrahmaputra-Meghna delta of India and Bangladesh are ecologically exceptional for mangrove habitats known as Sundarban Mangrove Forest. Ganga delta most fertile and vegetated alluvial land, also it's called 'Green Delta". The total area of Ganga delta is 105,000 Sq.km lies mostly $60 \%$ area under Bangladesh and $40 \%$ area is under West Bengal, India. Alluvial soil is creating major change in their people life because this area is suitable for growing forest, agricultural development as well as builds economically strong. In the Ganga delta lies mostly in the tropical climatic zone and this area has received 1500-2000 mm of rainfall in every year. In some eras, this area facing land changes because of Sea level rise. Sometimes people can change their habitation area. In the Indian region average annual temperature are $35^{\circ} \mathrm{C}$ in summer and $15^{\circ} \mathrm{C}$ in winter. Sometimes temperature falls at $10{ }^{\circ} \mathrm{C}$ in the month of January.

Low land value and Agricultural sustainability to breakdown the habitable suitability of South 24 Parganas districts (Fig. 1). But in this area facing a huge amount of problem like, they are connected to each other only by water. They have used boats for travelling to the main part of the land. Due to some decades, Sea Surface Change and increasing water level change can push for habitation abundant. After 2009, one tropical cyclone called "Aila" was hammering those areas. After this natural disaster, South 24 Parganas and the surrounding area have been adopted certain thinks for their sustainable livelihood. Amphan is one of them to create natural disaster in the month of May 2020. Life loss, economic loss, vegetation damaged and flood area the common effect on this area. Super cyclone Amphan affected this area with heavy precipitation, storm surge and strong wind. Same area has no mangrove forest to protect as a natural barrier of the coastal region. Mainly those areas have been more affected by this disaster.

\section{Materials and methods}

\section{Data used}

Sentinel-1 Ground Range Detected (GRD) images are using for food mapping and monitoring. In the cloud computing platform GEE, we used four Sentinel-1 radar dataset to estimate the Amphan related flood mapping. Sentine-1 VV (Vertical Transmit and Vertical Received) an VH (Vertical Transmit and Horizontal Received) descending mode dataset are used in Google Earth Engine platform. Landsat-8 OLI datasets are used for calculating the MNDWI map (Table 1). One pre-Amphan phase and two post-Amphan phase's satellite dataset are used for this study. Shuttle Radar Topography Mission (SRTM) DEM data is used for slope map generation in the study area (Fig. 2).

\section{Sentinel-1 dataset and pre-processing}

Sentinel-1 is consists of Level-1 GRD data (Table 1) processed backscatter coefficient $\left(\sigma^{\circ}\right)$ in decibels $(\mathrm{dB})$ using Google Earth Engine (GRD) (Sentinel-1 Algorithm). The backscatter coefficient represents the target backscattering 


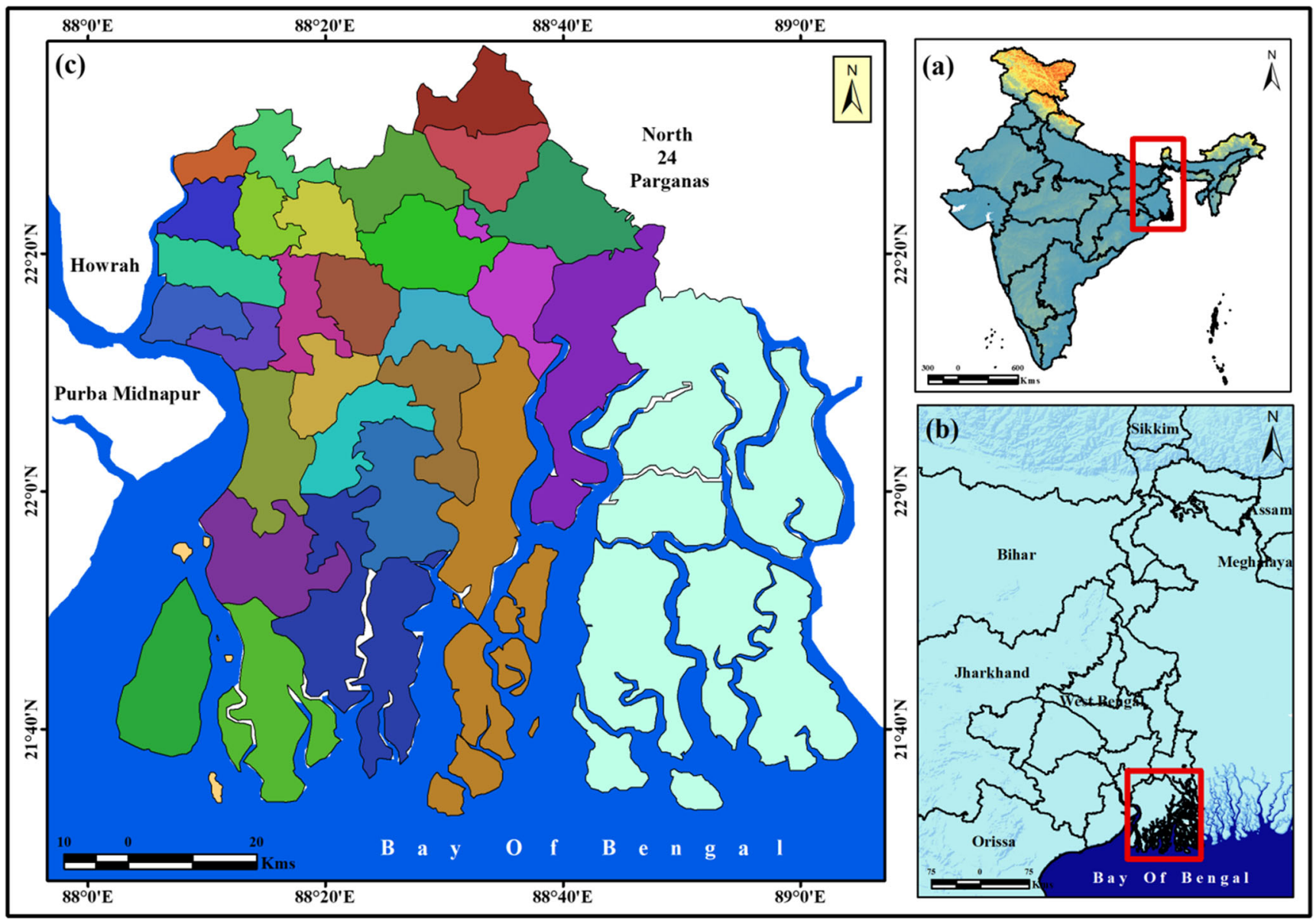

Fig. 1 Study area map. (a) Elevation and administrative boundary of India. (b) Elevation map and Topographical location of West Bengal state. (c) Administrative boundary of 29 blocks of South 24 Parganas district

area (radar cross-section) per unit ground area. Because it can vary by several orders of magnitude, it is converted to $\mathrm{dB}$ as $10 * \log 10 \sigma^{\circ}$ (GEE using Python). It measures whether the radiated terrain scatters the incident microwave radiation preferentially away from the SAR sensor $\mathrm{dB}<0$ ) or towards the $\mathrm{SAR}$ sensor $\mathrm{dB}>0$ ). This scattering behaviour depends on the physical characteristics of the terrain, primarily the geometry of the terrain elements and their electromagnetic characteristics.

\section{Thermal noise removal}

Atmospheric filtering is a technique used to reduce atmospheric noise by application of spatial filters and may include filtering techniques which remove the high frequency components from SAR observations (Goldstein and Werner 1998; Baran et al. 2003). Previous attempts have been made to categorise the atmospheric signal through the use of stochastic spatial filtering techniques.
Table 1 Dataset and google earth engine assets using this flood inundation study

\begin{tabular}{llll}
\hline Dataset & Used polarization/bands & Acquisition data & Spatial resolution \\
\hline Sentinel-1 ground range detected (GRD) & VV,VH & 16-May-20 & 10 \\
& & $22-$ May-20 & \\
& & $28-$ May-20 & \\
& & 07-Jun-20 & \multirow{2}{*}{ 17-Jan-20 } \\
Landsat-8 & B3, B6 & 24-May-20 & \\
& & 09-Jun-20 & \multirow{2}{*}{30} \\
Shuttle radar topography mission (SRTM) & SRTM V3 product & & \\
\hline
\end{tabular}


Fig. 2 Details methodology of the study area

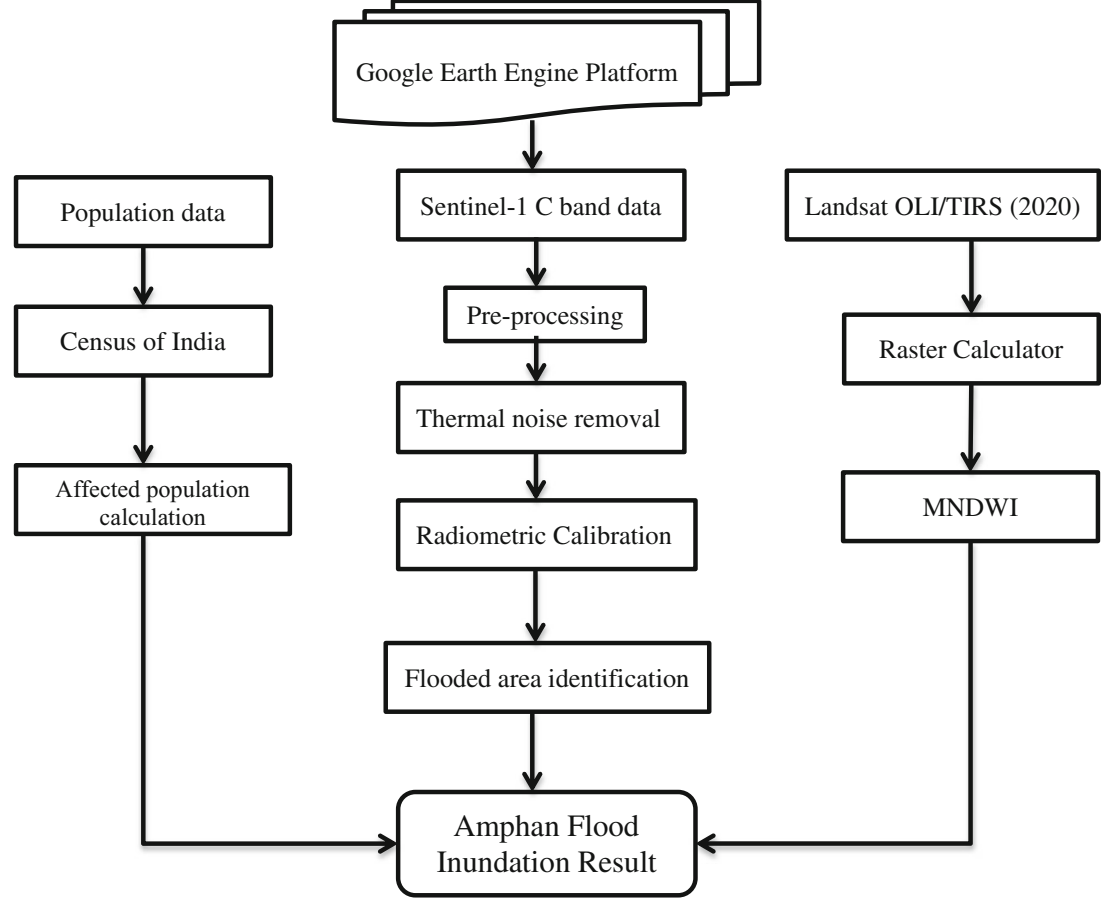

For example, an estimate of the auto-covariance functions, derived from interferometric observations over stable (non-deforming) regions, has been applied to the interferogram filtering process. However in general, they are limited to the observation of deformations of small spatial extent.

\section{Radiometric calibration}

Calibration techniques involve the use of independent observations of the atmosphere to correct the SAR observations. Approaches include corrections determined from GPS ground networks (Li et al. 2006), satellite radiometer data, as observed from instruments such as Moderate-Resolution Imaging Spectroradiometer (MODIS) and the Medium-Resolution Imaging Spectrometer (MERIS) (Li et al. 2006). Hanssen (2001) compared InSAR delays with precipitable water vapour derived from brightness and temperature variations in METEOSAT $6.7 \mu \mathrm{m}$ radiometer data. However, imaging radiometers are unable to observe the entire tropospheric water vapour column in the presence of cloud cover and this limits its applications.

Semi-empirical corrections to InSAR observations can also be made using ground temperature, humidity and pressure observations calibrated by radiosoundings, and this has been demonstrated successfully over the Etna volcano. Vertically stratified atmospheric models, where the delay depends only on altitude, have also been proposed (Beauducel et al. 2000).

\section{Terrain correction using SRTM $\mathbf{3 0}$ or ASTER DEM}

Sentinel-1 SAR data viewing angle was greater than 0 degrees and it's a side-looking geometry. Terrain correction is one of the geometric corrections for close as possible to the real-world. Range Doppler terrain correction is a geometric correction using Digital Elevation Model (DEM) and it's corrected by the location of each pixel (Filipponi 2019).

\section{Using Google earth engine}

In Google Earth Engine cloud computing platform, developed a framework to quantify and monitoring flooded area. C-band Level-1 Ground Range Detected (GRD) Sentinel-1 SAR images in ascending and descending orbits were used in this study. Some Algorithm used for selecting available data, filtering (Chen et al. 2017) before and after the change, histogram generation and statistical analysis using GEE platform. Export the results in GeoTIFF file format and histogram data export into CSV file. Each damage area was calculating some parts because the GEE platform estimate limited numbers of the pixel. The Sentinel-1A VH and VV polarization images were retrieved throughout the pre-flood period (20 April to 31 April 2020) and the peak flood period (18 May to 31 May 2020). The numerous pre-processing techniques were used to estimate the flooded area, like orbit correction, radiometric calibration, noise removal, orthorectification. Interferometric. 
Table 2 Flood affected area and affected population over the study area

\begin{tabular}{|c|c|c|c|c|c|}
\hline Block name & $\begin{array}{l}\text { Total area } \\
\text { (sq. km) }\end{array}$ & $\begin{array}{l}\text { Flooded area } \\
\text { (sq. } \mathrm{km})\end{array}$ & $\begin{array}{l}\text { Total population } \\
\text { (2001) }\end{array}$ & $\begin{array}{l}\text { Total population } \\
\text { (2011) }\end{array}$ & $\begin{array}{l}\text { Effected } \\
\text { population }\end{array}$ \\
\hline Baruipur & 226.2 & 43.75 & 351,439 & 433,199 & 149,886 \\
\hline Basanti & 404.2 & 129.53 & 278,592 & 336,717 & 117,850 \\
\hline Bhangore-II & 162.04 & 35.62 & 207,580 & 246,708 & 74,254 \\
\hline Bhangore-I & 153.62 & 69.87 & 204,380 & 264,443 & 85,467 \\
\hline Bishnupur-I & 116.4 & 59.86 & 206,370 & 232,365 & 75,842 \\
\hline Bishnupur-II & 81.71 & 48.29 & 190,636 & 214,531 & 69,584 \\
\hline Budge BudgeI & 26.55 & 12.354 & 99,945 & 112,908 & 52,412 \\
\hline Budge BudgeII & 78 & 38.975 & 173,446 & 192,134 & 68,645 \\
\hline Canning-I & 187.86 & 93.268 & 244,627 & 304,724 & 186,544 \\
\hline Canning-II & 214.93 & 104.89 & 195,967 & 252,523 & 142,564 \\
\hline $\begin{array}{l}\text { Diamond } \\
\text { Harbour-I }\end{array}$ & 68.43 & 35.96 & 133,366 & 156,166 & 114,587 \\
\hline $\begin{array}{l}\text { Diamond } \\
\text { Harbour-II }\end{array}$ & 95.59 & 62.751 & 165,233 & 190,801 & 135,478 \\
\hline Falta & 130.68 & 87.268 & 221,695 & 250,000 & 186,547 \\
\hline Gosaba & 2790.776 & 759.54 & 222,822 & 246,598 & 215,401 \\
\hline Joynagar-I & 131.01 & 59.895 & 219,090 & 219,090 & 154,785 \\
\hline Joynagar-II & 186.25 & 98.254 & 209,145 & 252,164 & 165,847 \\
\hline Kakdwip & 252.74 & 138.946 & 239,326 & 281,963 & 215,478 \\
\hline Kulpi & 210.83 & 156.86 & 242,752 & 283,197 & 235,475 \\
\hline Kultali & 306.18 & 187.254 & 187,989 & 229,053 & 175,842 \\
\hline Magrahat-I & 119.04 & 76.264 & 228,335 & 269,494 & 142,654 \\
\hline Magrahat-II & 136.93 & 89.562 & 262,092 & 304,744 & 195,642 \\
\hline Mandirbazar & 118.7 & 65.248 & 183,131 & 214,050 & 136,584 \\
\hline Mathurapur-I & 147.3 & 87.56 & 164,650 & 195,104 & 126,547 \\
\hline Mathurapur-II & 227.4 & 92.586 & 198,281 & 220,839 & 162,547 \\
\hline Namkhana & 370.61 & 198.485 & 160,627 & 183,000 & 132,547 \\
\hline Pathar Pratima & 484.47 & 239.732 & 288,394 & 331,823 & 213,947 \\
\hline Sagar & 282.11 & 154.254 & 185,644 & 212,037 & 185,472 \\
\hline Sonarpur & 120.63 & 53.96 & 167,408 & 219,863 & 78,452 \\
\hline $\begin{array}{r}\text { Thakurpukur } \\
\text { Mahestala }\end{array}$ & 63.08 & 23.54 & 136,903 & 176,203 & 25,478 \\
\hline
\end{tabular}

Wide (IW) swath mode was used with pixel spacing of $10 \mathrm{~m}$ and a swath of $250 \mathrm{~km}$. Average incident angles situated between $30^{\circ}$ and $45^{\circ}$. In polarized region Sentinel- 1 have dual $(\mathrm{HH} / \mathrm{HV})$ or single $(\mathrm{HH})$ polarized data available and in others area have dual (VV/VH) or single (VV) polarized data available (Sentinel-1 Observation Scenario- European Space Agency). Also Sentinel-1 Dual polarimetric data products will benefit users in agriculture, forest and land cover classification (https://sentinel.esa.int/web/sentinel/missions/sentinel-1/ observation-scenario).

\section{MNDWI calculation}

The dynamic thresholds are directly affected the overall accuracy of surface water area extraction. Modified normalised difference water index (MNDWI) was a formula proposed by $\mathrm{Xu}$ (2006) used to identify the water area. The formula is that (Eq. 1):

$$
M N D W I=\frac{\text { Green }-S W I R 1}{\text { Green }+ \text { SWIR1 }}
$$

The projected water extraction technique applied Modified Normalized Difference Water Index (MNDWI) method is combination with the adaptive dynamic threshold. The MNDWI was calculated using the satellite image and the separated water bodies area from background using segmentation technique and select the proper samples. 


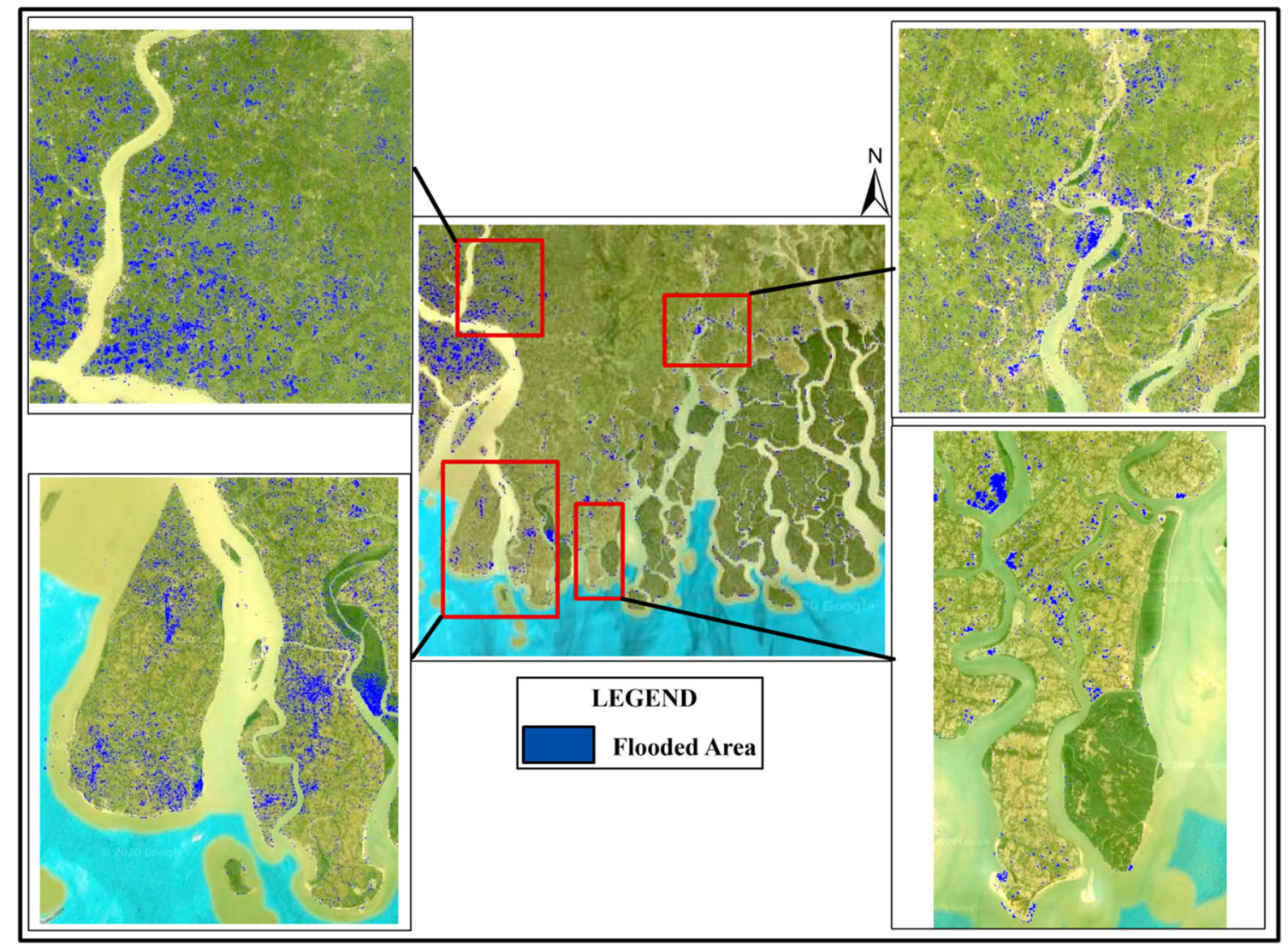

Fig. 3 Flood inundation area over South 2 Parganas district of West Bengal. Blue colour is showing the flooded area

\section{Results and discussion}

Amphan cyclone is mainly affected in the coastal parts of South 24 Parganas district. Namkhana, Kakdwip, Sagar, Pathar Pratima, Basanti, Kultali and Mathurapur blocks are affected due to this cyclone. The Sentinel-1 C band SAR data used for flood inundation on South 24 parganas district. Most part of this study area has been affected from 16 May to 24
May 2020 (Fig. 3). The flood inundation continuously hammering the West Bengal coastal followed by Odisha and Bangladesh (The country). The coastal area, road, transportation system were damaged by this super cyclone (Table 2). Basanti (129.53 sq.km), Canning-II (104.89 sq.km), Falta (87.268 sq.km), Gosaba (759.54 sq.km), Kakdwip (138.946 sq.km), Kultali (187.254 sq.km), Mograhat-II (89.562 sq.km), Namkhana (198.485 sq.km), Patharpatima
Fig. 4 Different between the total area and flooded area over 29 block of South 24 Parganas district

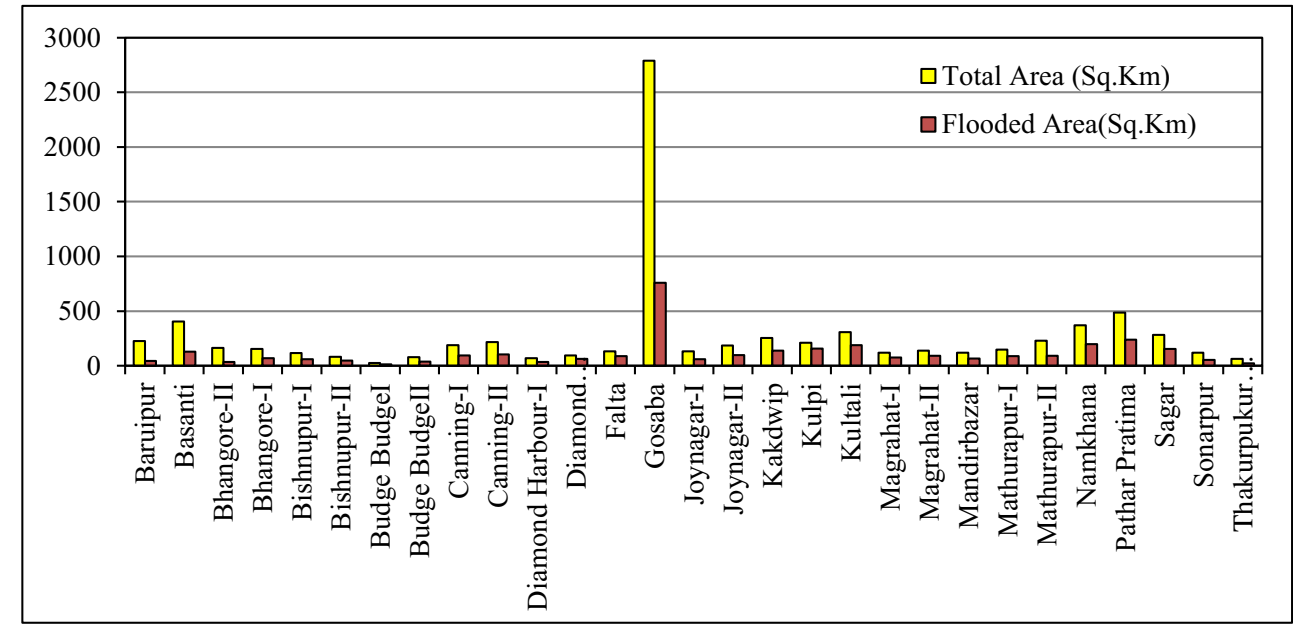




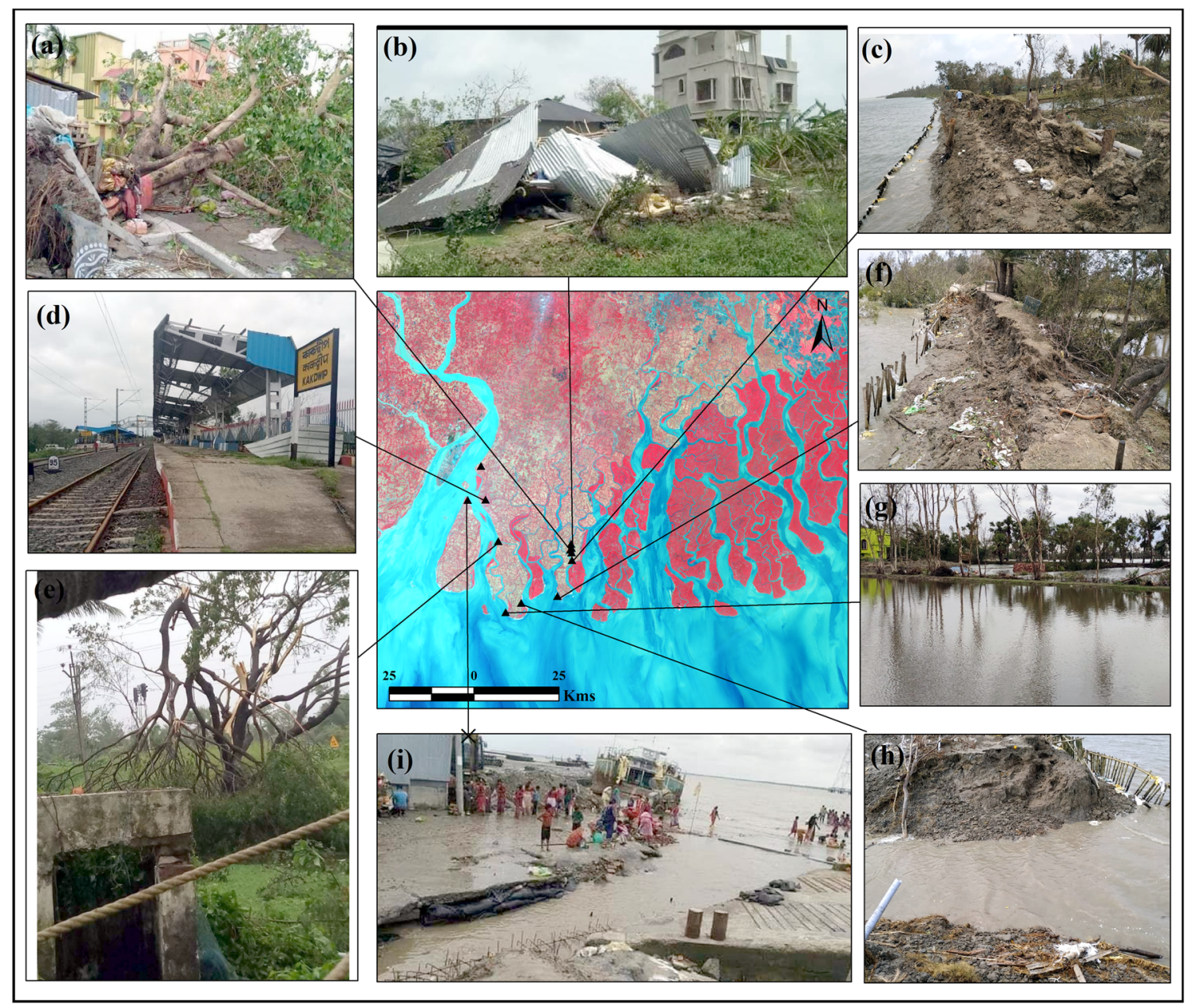

Fig. 5 The super cyclone effect over the study area. (a-b) Amphan affected area, (c) Riverbank erosion during Amphan in L-Block, (d) Kakdwip railway station, (e) Namkhana area, (f) Riverbank erosion on

(239.732 sq.km), Sagar (154.254) and Sonarpur (53.96 sq.km) area are flood during this cyclonic periods (Fig. 4). Cropland is affected during flood inundation. Similarly flood affected population primarily Baruipur (149,886 people), Basanti (117,850 people), Canning-I (186,544 people), Falta (186,547 people), kakdwip (215,478 people), Magrahat-II
G-plot, (g) flood inundated area near bakkhali location, (h) flood water affected the manmade soil bridge and (i) Sagar ferry ghat during Amphan

(195,642 people), Patharpatima (213,947 people) and Sagar (185,472 people) (Fig. 5). The relation between the affected population and flooded area, $\mathrm{R}^{2}$ shows the value 0.2642 (Fig. 6). During COVID-19 pandemic, maintaining social and physical distance is the main problem in cyclone shelter house and cyclone relief camp.
Fig. 6 Scatter plot showing the relation between affected population and flooded area over 29 blocks of South Parganas district

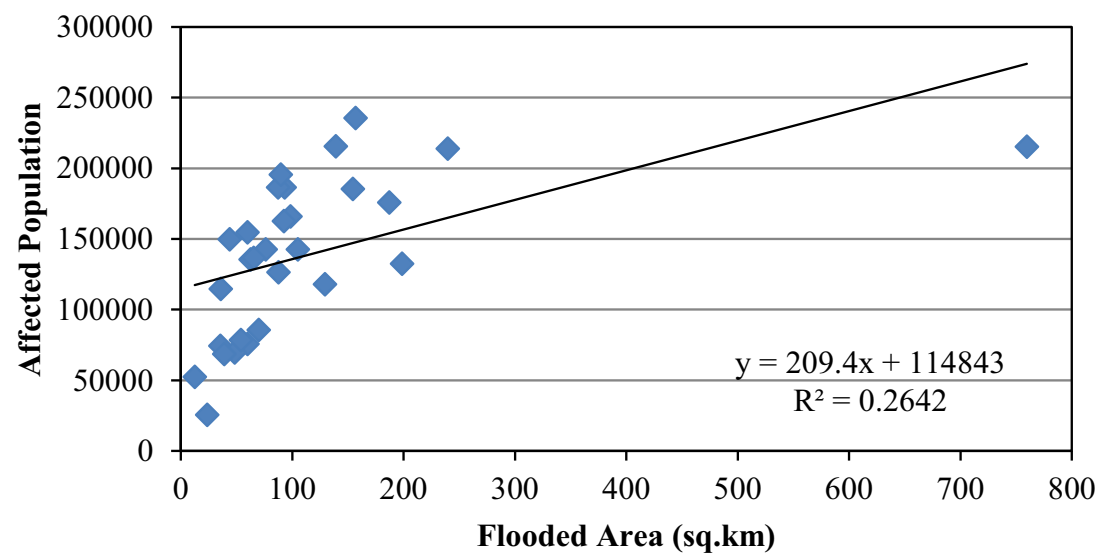


Fig. 7 Comparison and validation of flood inundation over the stud area using MNDWI method. Map A1 showing preAmphan MNDWI for 17 January and Post-Amphan (B1) 25 May, (C1) 9 June in Kakdwip and Mousuni Island area. Second map (A2, B2 and C2) is showing Southern part of G-plot and third map (A3, B3 and C3) is showing southern part of Sagar Island

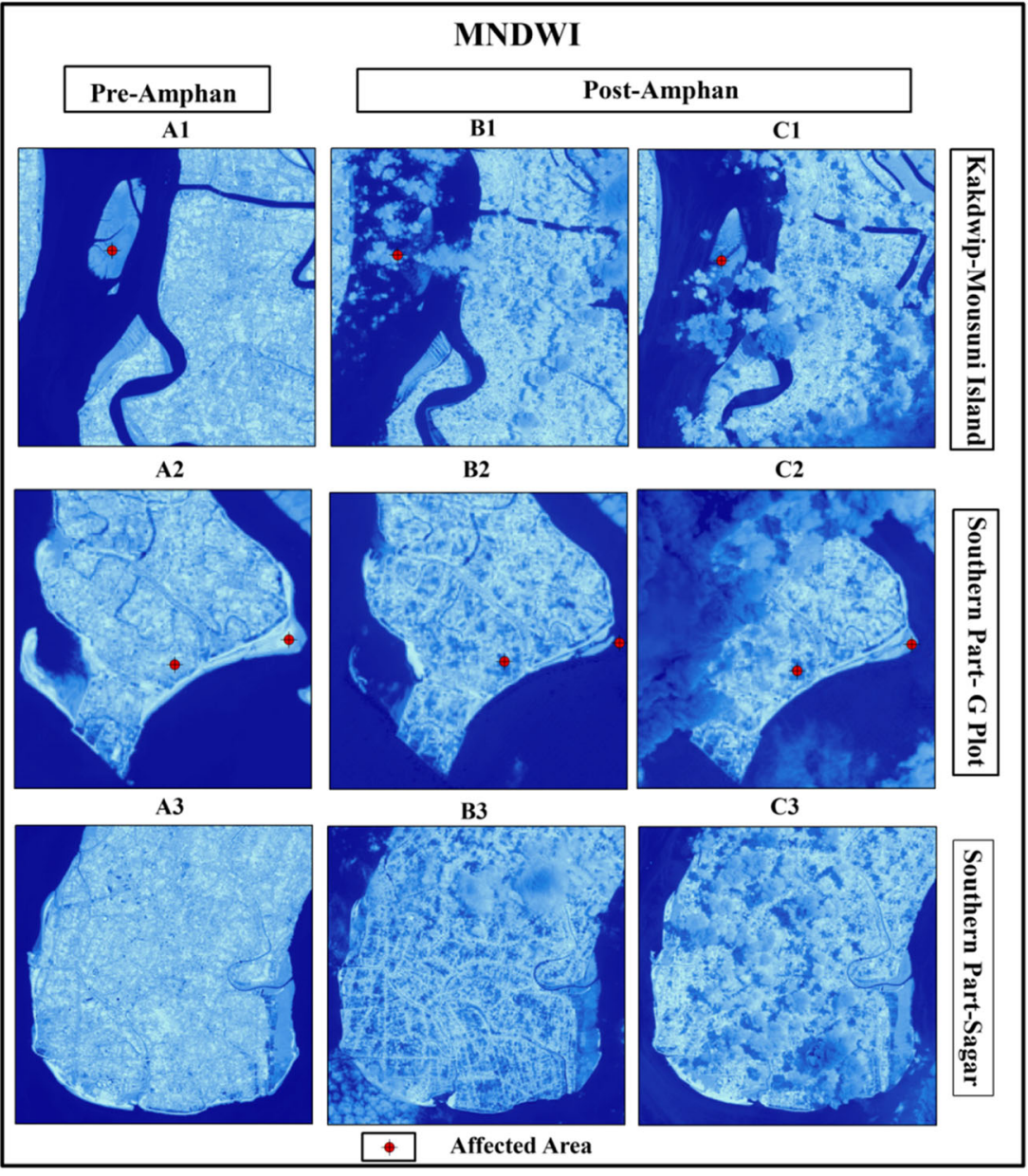

\section{Population suffering from Amphan}

Around 21,560 Sq.km areas have been affected by this deadly cyclone and millions of people have been homeless. They lost their home and suffer many problems in this situation. Farmers also lost their cropped area like paddy, mangoes and lychee during the harvest time. As per 2011 census, Ghoramara Island 1 has around 5000 population but nowadays only 650 people have living on this island. Rapid erosion and seawater level rise are affected in this area. Several houses are inundated into the remote settlement on Sundarban area during this cyclone. Sundarban is the ecologically fragile zone and this region has recovered from most of the damaged caused by past cyclone like Aila, Fani and Bulbul. During COVID-19, Amphan again damaged the mangrove ecosystem. According to West Bengal government, around 21,560 sq.km area has been affected by this cyclone. Three lakh people have been evacuated to relief shelters in West Bengal. A super cyclone Amphan, the Bay of Bengal is facing after 21 years. Affected areas are Bangladesh and West Bengal, Odisha. Just in $24 \mathrm{~h}$. Kolkata is facing $250 \mathrm{~mm}$ rainfall. Many areas are not connected with electricity and water supply. The Island named Sagar. Ghoramara, G-plot, L-block, Mousuni, and gosaba were not connected to each other's because for their transportation problem (Fig. 8). The boat is the only transportation system to join the mainland. In this COVID- 19 pandemic movement, this super cyclone triggers food supply chain, people safety and also the massive economic loss. Around 1 trillion rupees is loss in infrastructure and crops production. Baruipur, Patharpatima, Kakdwip, Namkhana, Thakurpukur Maheshtala, Kulpi and Diamond harbour are the most populated area on South 24 Parganas.

\section{Accuracy assessment of flood mapping}

To identify the authenticity and accuracy of this flood monitoring, a flood map evaluation is implemented created on visual interpretation and testing samples that are retrieved from the Modified Normalized Difference Water Index (MNDWI). MNDWI increased the high reflectance of water by using Green wavelength and decreased low reflectance in Mid-infrared wavelength of the water features. Using this index, easily identify the 


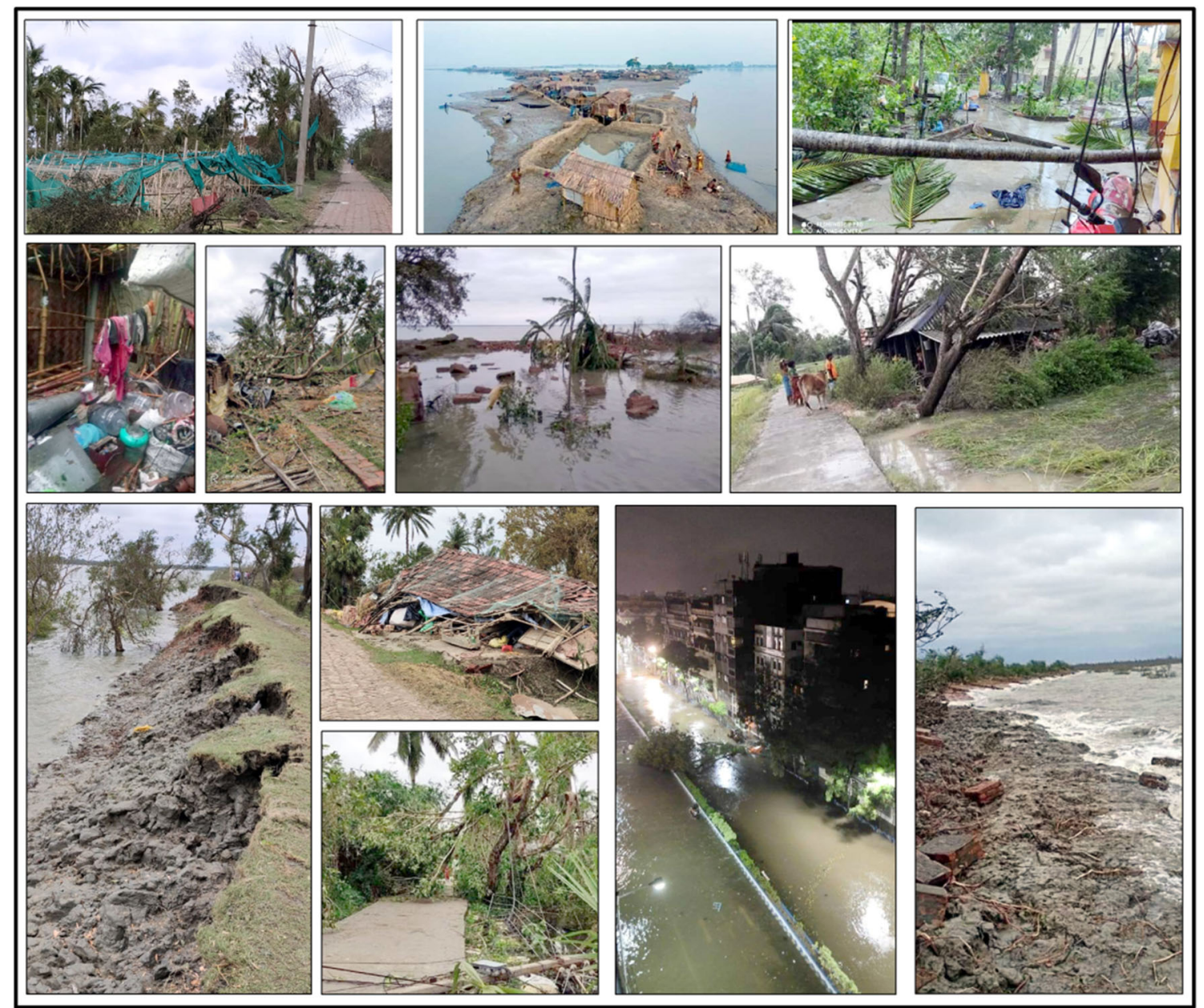

Fig. 8 Super cyclone Amphan affected area in the various parts of South 24 Parganas district

water area because of their values. Water area shows high positive values and other vegetation, soil, land area and non-water area shows zero to negative value on this index. The accessible multispectral Landsat- 8 images area available for 24 May and 9 June (Post Amphan). The large sections of those two images are thick cloud cover (ranging from $30 \%$ to $70 \%$ ). Pre Amphan image is used on 17 January 2020 to identify the water area change due to this cyclone (Fig. 7). Selected three parts of South 24 Parganas area are shows the water area change using Modified Normalized Difference Water Index (MNDWI). Kakdwip-Mousuni Island, southern part of Sagar Island and Southern parts of G-plot are showing water increased due to Amphan cyclone. Coastal areas are mostly affected due to this cyclone. Mangrove deforestation and population pressure are directly affected by the land and cause several damages like that. The natural barrier mangrove forest is cut down for population pressure. The Modified Normalized Difference Water Index (MNDWI) is showing the water area in this study area.

\section{Conclusion}

Cyclones are the most effective and deathly natural hazard of coastal populated region. In between $100 \mathrm{~km}$ of every coastal area around $40 \%$ of people are living. Every year during the pre-monsoon and monsoon periods the cyclone is hammering the people life. Frequently affected areas are the coastal region and the people. Social vulnerability and several economic losses during the cyclone and huge amount of vegetation damaged due to flood and superstorm. In the year of 2009, 'Aila' was hammering in Bay of Bengal coast and massive loss of the southern parts of West Bengal and Bangladesh. Amphan named by Thailand and it's affected in the Bay of.

Bengal during 20th may 2020. As per the state report, around 72 people have died in West Bengal and 12 people in Bangladesh. The Enormous quantity of economic loss and people was homeless during the cyclone. This cloud computing algorithm based platform can assistance for monitoring environmental change detection. GEE platform is additionally cost-effective and humble to use. In future, 
remote sensing data and cloud-computing technologies will benefit for land monitoring, environmental change and flood monitoring on the global scale. The accessibility of satellite data will help the user for manipulative the environmental degradation or natural disaster to spread the bulletin to everybody for the problem we will face in the future. In this study reported the recent Amphan related flood inundation in the lower part of West Bengal. This natural hazard study is necessary for future adaptation, awareness, preparedness, relief camp, cyclone shelter house and self-resilience of the entire coastal region.

Acknowledgements We would like to thank the Vidyasagar University to support this research. The authors are also thankful to the ESA Copernicus hub for Sentinel-1 data availability, Goole for using Google Earth Engine data processing and USGS for Landsat imageries.

\section{Declarations}

Conflict of interest On behalf of all authors, the corresponding author states that there is no conflict of interest.

\section{References}

Baran M, Gatalskaya VI, Szymczak R, Shiryaev SV, Barilo SN, Piotrowski K et al (2003) Magnetic phase transitions in TbBaCo2O5. 5 single crystals. J Phys: Condens Matter 15(50): 8853. https://doi.org/10.1088/0953-8984/15/50/016

Beauducel F, Briole P, Froger JL (2000) Volcano-wide fringes in ERS synthetic aperture radar interferograms of Etna (1992-1998): deformation or tropospheric effect? J Geophys Res: Solid Earth 105(B7): 16391-16402. https://doi.org/10.1029/2000JB900095

Canty MJ, Nielsen AA, Conradsen K, Skriver H (2020) Statistical analysis of changes in Sentinel-1 time series on the google earth engine. Remote Sens 12(1):46. https://doi.org/10.3390/rs12010046

Carreño Conde F, De Mata Muñoz M (2019) Flood monitoring based on the study of Sentinel-1 SAR images: the Ebro River case study. Water 11(12):2454. https://doi.org/10.3390/w11122454

Chen B, Liu X, Zhao H, Principe JC (2017) Maximum correntropy Kalman filter. Automatica 76:70-77. https://doi.org/10.1016/j. automatica.2016.10.004

Colletta NJ. (2004) Human-driven disasters violent conflict, terrorism and technology. Inter-American Development Bank. https:// publications.iadb.org/publications/english/document/HumanDriven-Disasters-Violent-Conflict-Terrorism-and-Technology.pdf

Conradsen K, Nielsen AA, Schou J, Skriver H (2003) A test statistic in the complex Wishart distribution and its application to change detection in polarimetric SAR data. IEEE Trans Geosci Remote Sens 41(1):4-19. https://doi.org/10.1109/TGRS.2002.808066

Dostálová A, Hollaus M, Milenković M, Wagner W (2016) Forest area derivation from sentinel-1 data. ISPRS Ann Photogramm Remote Sens Spat Inf Sci 3:227 FAQ-Google Earth Engine, 2020. Available online: https://earthengine.google.com/faq/
Filipponi F (2019) Exploitation of Sentinel-2 time series to map burned areas at the national Level: a case study on the 2017 Italy wildfires. Remote Sens 11(6):622

Gan TY, Zunic F, Kuo CC, Strobl T (2012) Flood mapping of Danube River at Romania using single and multi-date ERS2-SAR images. Int J Appl Earth Obs Geoinf 18:69-81. https://doi.org/10.1016/j.jag. 2012.01.012

Goldstein RM, Werner CL (1998) Radar interferogram filtering for geophysical applications. Geophys Res Lett 25(21):4035-4038. https:// doi.org/10.1029/1998GL900033

Gorelick N, Hancher M, Dixon M, Ilyushchenko S, Thau D, Moore R (2017) Google earth engine: planetary-scale geospatial analysis for everyone. Remote Sens Environ 202:18-27

Hanssen RF. (2001) Radar interferometry: data interpretation and error analysis (vol. 2). Springer Science \& Business Media. https://books. google.co.in/books?hl=en\&lr=\&id=bqNkJUk4wtMC\&oi= f n d \& p g $=$ P A $4 \&$ o t $\mathrm{s}=8$ P d r n E 9 R \& s i g $=$ MM8RF3Pd4oypEP1uvIx7BmwY5Yw\&redir_esc=y\#v= onepage $\& \mathrm{q} \& \mathrm{f}=$ false

Kumar L, Mutanga O (2018) Google earth engine applications since inception: usage, trends, and potential. Remote Sens 10(10):1509. https://doi.org/10.3390/rs10101509

Kwak YJ (2017) Nationwide flood monitoring for disaster risk reduction using multiple satellite data. ISPRS Int J Geo Inf 6(7):203. https:// doi.org/10.3390/ijgi6070203

Li XH, Zhou P, Li CY, Zhou HY, Deng FG (2006) Efficient symmetric multiparty quantum state sharing of an arbitrary m-qubit state. $\mathrm{J}$ Phys B: At Mol Opt Phys 39(8):1975

Mohapatra M (2015) Cyclone hazard proneness of districts of India. J Earth Syst Sci 124(3):515-526. https://doi.org/10.1007/s12040015-0556-y

Mutanga O, Kumar L (2019). Google Earth Engine Applications. Remote Sensing, 11(5). https://doi.org/10.3390/rs11050591

Olorunfemi FB, Raheem UA (2013) Floods and rainstorms impacts, responses and coping among households in Ilorin, Kwara Stat. J Educ Soc Res 3(4): 135

Otsu N (1979) A threshold selection method from gray-level histograms. IEEE Trans Syst Man Cybern 9(1):62-66

Rahman MR, Thakur PK (2018) Detecting, mapping and analysing of flood water propagation using synthetic aperture radar (SAR) satellite data and GIS: a case study from the Kendrapara District of Orissa State of India. Egypt J Remote Sens Space Sci 21:S37S41. https://doi.org/10.1016/j.ejrs.2017.10.002

Van Niekerk D (2006) Disaster risk management in South Africa: the function and the activity-towards an integrated approach. Politeia 25(2):96-116 https://www.ingentaconnect.com/content/sabinet/ polit/2006/00000025/00000002/art00002

Voigt S, Martinis S, Zwenzner H, Hahmann T, Twele A \& Schneiderhan T. (2009) Extraction of flood masks using satellite based very high resolution SAR data for flood management and modeling. In: RIMAX contributions at the 4th international symposium on flood defence (ISFD4). Deutsches GeoForschungsZentrum GFZ. https:// gfzpublic.gfz-potsdam.de/rest/items/item_6040_8/component/file $6041 /$ content

Xu H (2006) Modification of normalised difference water index (NDWI) to enhance open water features in remotely sensed imagery. Int $\mathrm{J}$ Remote Sens 27(14):3025-3033 